\title{
Transmesocolic Herniation of Small Bowel Following Colonic Interposition
}

\author{
FAROOQ P. AGHA, M.D. \\ Department of Radiology \\ University of Michigan Hospitals, Ann Arbor, Michigan USA 48109.
}

\section{INTRODUCTION}

Visceral esophageal substitution using colon, though a well established procedure, is now performed less frequently than in the past ${ }^{1}$. Since the earliest descriptions of colonic interposition by Kelling ${ }^{2}$ and Vulliet ${ }^{3}$, numerous reports have been published regarding technical variations of the procedures and its efficacy in the management of benign as well as malignant lesions of the esophagus ${ }^{4-7}$. Few reports, however, deal with complications ${ }^{8-10}$. We have reviewed our experience with 45 patients undergoing colonic interposition between July, 1973, and December, 1983, at the University of Michigan Hospitals, Ann Arbor. Parts of this review are reported elsewhere ${ }^{11}$. The present report focuses on iatrogenic changes in small bowel following colonic interposition. Of these, most important are iatrogenic internal hernias through defects in the mesocolon causing small bowel obstruction.

\section{CASE REPORTS}

Case 1.

A 26-year-old mentally retarded male developed a caustic-induced long stricture of the esophagus. Attempts at dilatation caused esophageal perforation. A long segment colonic interposition using an isoperistaltic left colon

\section{Key Words:}

Colonic interposition; small bowel obstruction; iatrogenic internal hernia; mesocolic hernia.

\author{
Address reprint requests to: \\ Faroog P. Agha, M.D. \\ Box 013, Department of Radiology, \\ University Hospital, \\ 1405 East Ann Street, \\ Ann Arbor, MI 48109.
}

supplied by the ascending branch of the left colic artery was performed in June, 1976. The immediate postoperative course was unremarkable. Two months after operation he complained of intermittent abdominal pain accompanied by nausea and vomiting. Abdominal radiographs

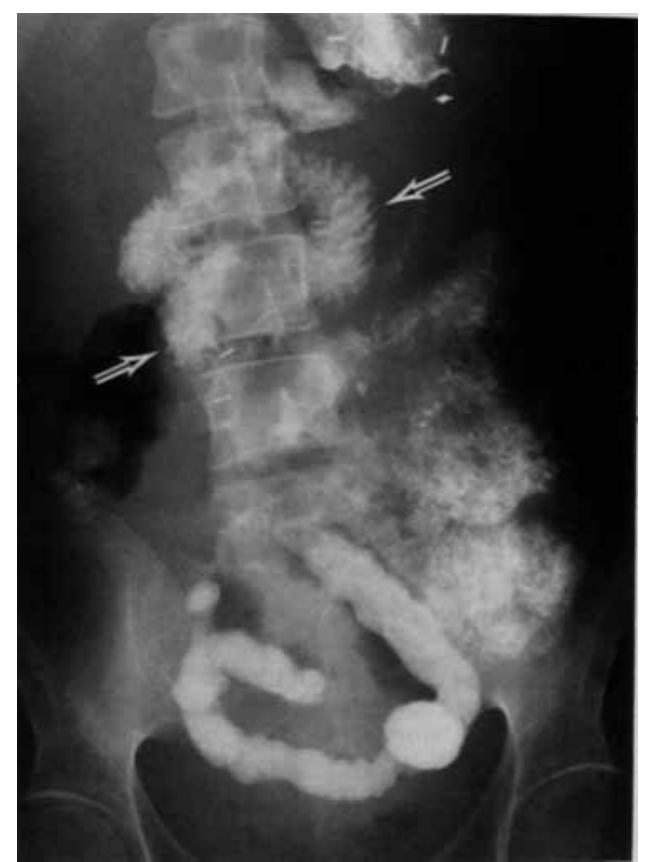

FIGURE 1. - Case 1. A barium small bowel follow through show abnormal grouping of loops of small bowel in the upper mid abdomen (arrows) representing herniated bowel through a defect in the mesocolon at operation.

Accepted for publication on 23rd October, 1984.

Australasian Radiology, Vol. XXIX, No. 2, May, 1985 
TRANSMESOCOLIC HERNIATION OF SMALL BOWEL

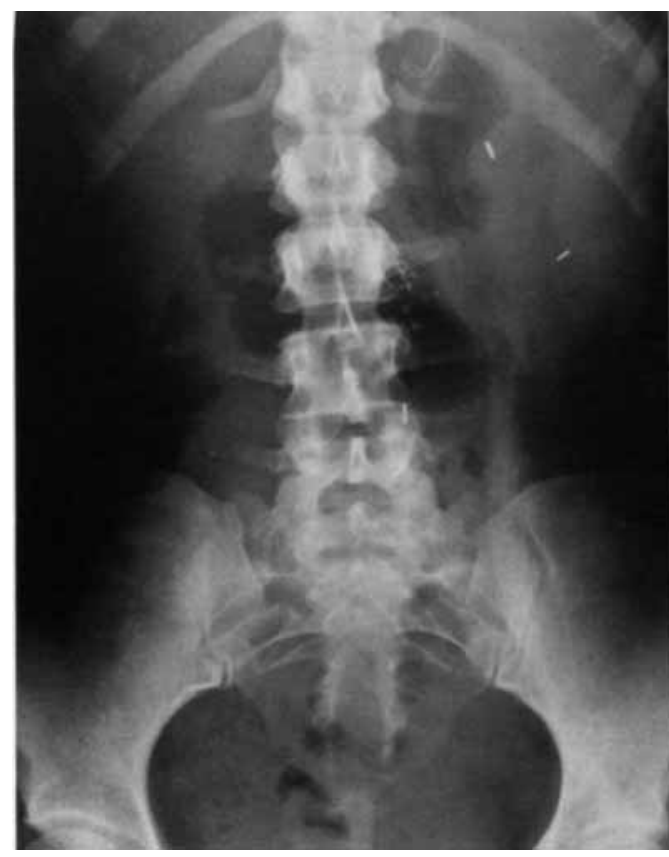

FIGURE 2A

FIGURES 2A-C. - Case 2. A. \& B. Supine and uprigh views of the abdomen show a distended loop of small bowel in the upper mid abdomen with differential air fluid levels. C. A similar appearance was seen five days earlier when patient developed abdominal pain. This was a herniated loop of small bowel through a defect in the mesocolon at operation causing intermittent high small bowel obstruction.

revealed distended loops of small bowel. A small bowel follow-through with barium sulfate mixture revealed abnormal grouping of loops of small bowel in the upper mid abdomen (Figure 1), unchanged in location and configuration in all radiographs. This was not appreciated at the time of examination. However, due to clinical symptoms of intermittent small bowel obstruction, the patient was operated upon. At surgery an internal hernia consisting of a loop of small bowel herniated through a defect in the mesocolon was found. This segment of small bowel was infarcted. Resection with end-to-end anastomosis was performed. The defect in the mesocolon was repaired. The postoperative course was uneventful.

\section{Case 2.}

A 25-year-old female developed a causticinduced long stricture of the esophagus complicated by reflux esophagitis. She underwent long segment colonic interposition using a left colon isoperistaltic segment supplied by the

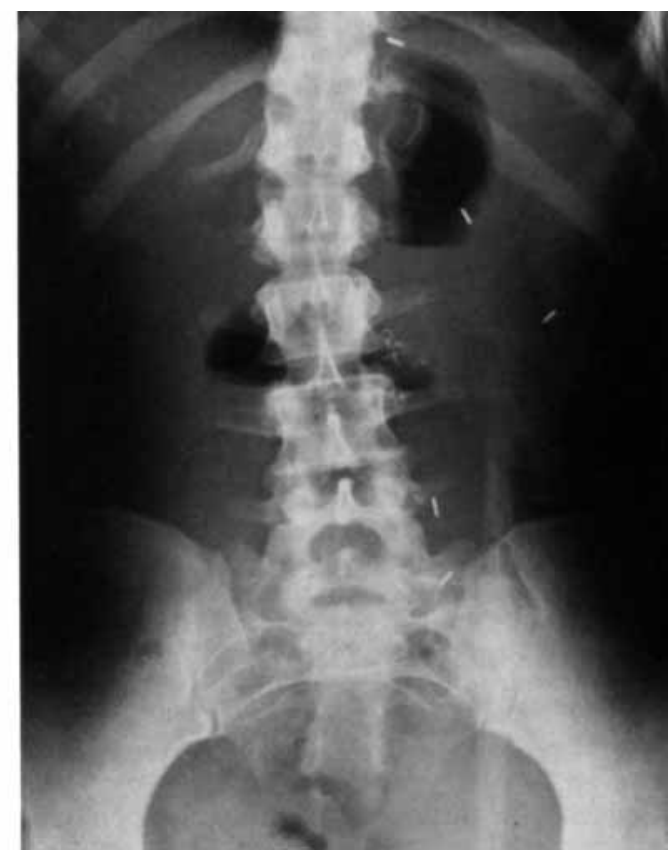

FIGURE 2C

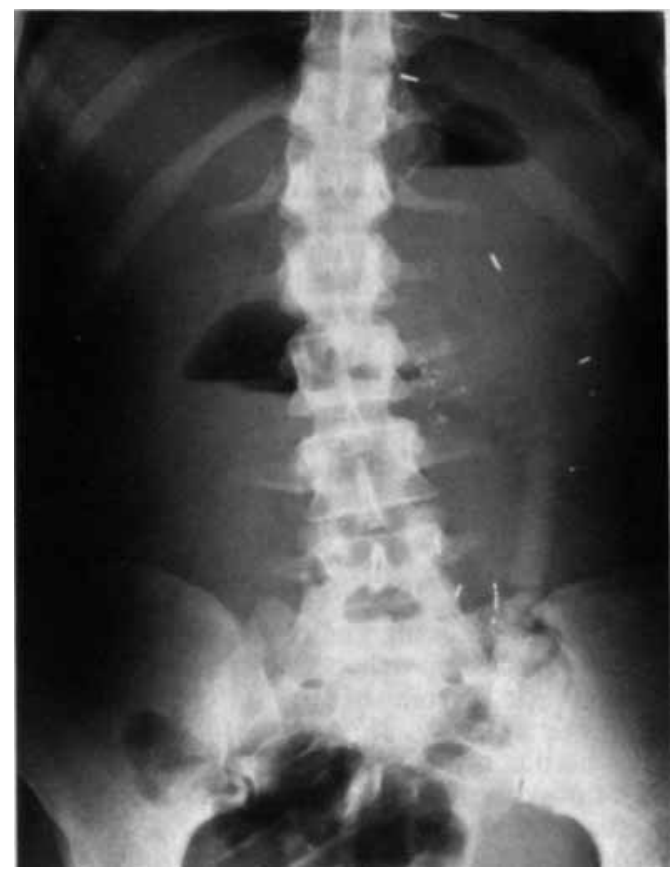

FIGURE 2B 


\section{F.P. AGHA}

ascending branch of the left colic artery in April, 1975. On the seventh postoperative day she developed intermittent abdominal pain without distention, nausea, or vomiting. The abdominal radiographs revealed a single distended loop of small bowel in the upper abdomen. The symptoms subsided and recurred again five days later. The pain was then accompanied by abdominal distention, nausea, and vomiting. Abdominal radiographs (Figure 2) revealed a single distended loop of small bowel with an air-fluid level present in the same location as in the radiograph obtained five days earlier. With a clinical diagnosis of high partial small bowel obstruction, a laparotomy was performed. At operation a loop of small bowel was found to have herniated through a defect in the mesocolon. The bowel was viable and no resection was done. The defect in the mesocolon was closed. The remainder of her postoperative course was unremarkable.

\section{Case 3.}

A 24-year-old female developed severe causticinduced strictures of the esophagus and stomach. She underwent transhiatal esophagectomy, partial gastrectomy, and long segment colonic interposition using isoperistaltic left colon supplied by the ascending branch of the left colic artery with pharyngocolic and cologastric anastomosis in January, 1977. The postoperative course was uneventful until two years later when she developed symptoms of intermittent small bowel obstruction. A small bowel follow through revealed angulation of loops of small bowel due to adhesions and probably due to traction on the small bowel mesentery. A loop of small bowel was seen high in the midline above the level of the transverse mesocolon. At operation a loop of small bowel was found herniated through a defect in the mesocolon causing an internal hernia as well as several adhesions. The bowei was viable, no resection was performed, and the defect in mesocolon was closed. Postoperatively, the patient did well.

\section{DISCUSSION}

Iatrogenic internal hernia following gastric surgery has been well documented ${ }^{12-15}$. Retroanastomotic hernia of the efferent limb in retrocolic isoperistaltic anastomosis as well as rare herniation of both limbs of a gastrojejunostomy through the opening in the transverse mesocolon in retrocolic anastomosis are well recognized postoperative complications. Congenital and acquired defects and areas of

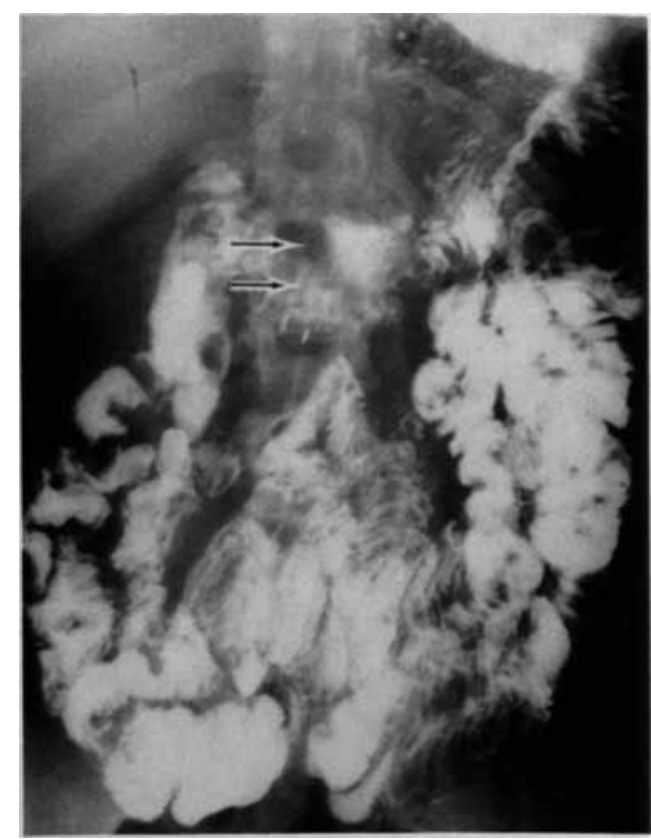

FIGURE 3. - Case 3. A barium small bowel follow through show abnormally high midline location of a loop of small intestine above the anatomic location of transverse mesocolon (arrows). Angulation of loops due to adhesions and traction on the small bowel mesentery is present below the herniated loop of the small bowel.

weakness in the mesocolon serve as hernial rings for a variety of intraabdominal herniations well documented in the literature ${ }^{16-18}$. In comprehensive reviews of internal abdominal hernia and iatrogenic hernias by Ghahremani and Meyers ${ }^{19,} 20$ no mention is made of small bowel herniation through defects in the mesocolon following colonic interposition. Small bowel obstruction following colonic interposition was reported by Osborne et $a^{21}$; however, they made no mention of the mechanism of obstruction. It is presumed that being the most common cause of postoperative small bowel obstruction postoperative adhesions were the causative factor in their case report. Markowitz ${ }^{13}$ has pointed out that "performance of any anastomosis within the abdominal cavity may result in creation of an iatrogenic hernial ring". It is standard surgical procedure and practice to close any visible defects of the subtending mesentery or mesocolon after all bowel anastomosis in the abdomen.

The most common cause of small bowel ob-

Australasian Radiology, Vol. XXIX, No. 2, May, 1985 


\section{TRANSMESOCOLIC HERNIATION OF SMALL BOWEL}

struction following any type of abdominal surgery is postoperative adhesions. Iatrogenic internal hernia of small bowel following colonic interposition reported in three patients represents a unique complication and cause of small bowel obstruction. Awareness of this entity in patients undergoing colonic interposition, prompt recognition, and early surgical treatment will prevent extensive and irreparable intestinal reduce the damage and reduce the high rate of mortality associated with obstructing internal hernias.

\section{ABSTRACT}

This report focuses on iatrogenic transmesocolic hernia causing small bowel obstruction following colonic interposition. Of 45 patients undergoing visceral esophageal substitution using colon, three developed small bowel obstruc-. tion due to internal herniation of a loop of small bowel through a defect in the mesocolon. Awareness of this unique cause of small bowel obstruction following colonic interposition and institution of early surgical treatment will prevent irreparable intestinal damage associated with internal hernias.

\section{ACKNOWLEDGEMENT}

The authors thank Mark B. Orringer, M.D., Department of Surgery, Section of Thoracic Surgery for his kind permission to report on these patients, and Ms Juanita Cantrell for meticulously typing this manuscript.

\section{REFERENCES}

1. Postlewait RW. Colonic interposition for esophageal substitution. Surg Gynecol Obstet 1983; $156: 377-383$.

2. Kelling G. Osteophagoplastik mit Hilfe des Querkolon. Zentralbl Chir 1911; $38: 1209-1212$.

3. Vulliet H. De l'esophagoplastic et des diverses modifications. Semin Med 1911; $31: 529-532$.

4. Yadin SS. Surgical construction of 80 cases of artificial esophagus. Surg Gynecol Obstet 1944; 78 : 561-583.
5. Belsey R. Reconstruction of the esophagus with left colon. J Thorac Cardiovasc Surg 1965; 49 : 33-35.

6. Wilkins EW. Long segment colon substitution for the esophagus. Ann Surg 1980; $192: 722-725$.

7. Orringer MB, Kirsh MM and Sloan $H$. New trends in esophageal replacement for benign disease. Ann Thorac Surg 1977; $23: 409-416$.

8. Louhimo L, Posila M and Visakorpi JK. Late gastrointestinal complications in patients with colonic replacement of the esophagus. J Ped Surg 1969; 4 : 663-673.

9. Postlewait RW. Surgery of the Esophagus. New York: Appleton-Century Croft, 1979; 460-463.

10. Huguier M, Gordin F, Maillard JN and Lortat-Jacob JL. Results of 117 esophageal replacements. Surge Gynecol Obstet 1970; 130:1054-1058.

11. Agha FP and Orringer MB. Colonic interposition: radiologic evaluation. Amer J Roentgenol 1984; 142 : 703-708.

12. Hardy JD. Problems associated with gastric surgery: a review of 604 consecutive patients with annotation. Amer J Surg 1964; 108 : 699-716.

13. Markowitz AM. Retroanastomotic hernia. In: Nyhus LM, Harkins HN, [eds] Hernia. Philadelphia: J.B. Lippincott Co., 1964; 607-616.

14. Morton CB II, Allrich EM and Hill LK III. Internal hernia after gastrectomy. Amer J Surg 1955; 141 : 759.

15. Sebesta DG and Robson MC. Peterson's retroanastomotic hernia. Amer J Surg 1968; 116 : 450-453.

16. Bertelsen $S$ and Christiansen $J$. Internal hernia through mesenteric and mesocolic defects. A review of literature and report of two cases. Acta Chir Scand $1967 ; 133: 426-428$.

17. Housman GH and Morton SA. Intraabdominal hernia. Report of a case and review of the literature. Arch Surg 1939; $39: 973-986$.

18. Mueller EC. Congenital internal hernia. Amer J Surg 1959; $97: 201-204$.

19. Ghahremani GG and Meyers MA. Internal abdominal hernias. Curr Probl Surg 1975; 5(6) : 3-30.

20. Ghahremani GG and Meyers MA. Iatrogenic abdominal hernias in: Iatrogenic Gastrointestinal Complications. Meyers MA, Ghahremani GG (Eds.). New York - Springer Verlag Publishers, 1981, Chapter 11, pp. 269-278.

21. Osborne MP, Griffith JD and Shaw HJ. Colon inter position in the management of upper gastrointestinal cancer. Cancer 1982; 50(10) : 2235-2242. 